\title{
Cold-water Coral Microbiome and Environmental Microbial Communities in a Remote NE Atlantic Submarine Canyon Setting: Microbial Diversity, Coral Health and Prospects
}

\author{
J. K. M. Appah ( $\square$ john.appah@ucc.ie) \\ University College Cork \\ E. Dillane \\ University College Cork
}

A. Lim

University College Cork

R. 0 'Riordan

University College Cork

L. O’Reilly

University College Cork

L. Macedo

University College Cork

A. J. Wheeler

University College Cork

\section{Research Article}

Keywords: Next generation sequencing, microbiome, submarine canyons, Lophelia pertusa, bacteria, coldwater corals, Ireland

Posted Date: February 15th, 2021

DOI: https://doi.org/10.21203/rs.3.rs-192160/v1

License: (c) (1) This work is licensed under a Creative Commons Attribution 4.0 International License. Read Full License 


\section{Abstract}

In the Porcupine Bank Canyon, Lophelia pertusa and Madrepora oculata are the main framework-forming corals producing three dimensional structures which provide a home for a range of benthic fauna and microbial communities. To understand the roles and functions that microbes perform in coral health in the Porcupine Bank Canyon, three groups of samples (corals, sediment and water) were collected between 600-800 m depth. DNA was extracted from these samples and metabarcoding was performed on the V3-V4 region of the 16S RNA gene using Illumina technology. The coral microbiome showed greater microbial diversity than both the surrounding sediment and water communities. The genera Pseudomonas, Pseudoalteramonas and Photobacterium were the bacterial communities conserved at $100 \%$ coverage of coral samples whereas at the order-level classification Clostridiales, Bacteroidales, Flavobacteriales, Rhodobacterales and Rickettsiales were in high abundance in all the coral samples. A disproportionate distribution of probiotic and pathogenic bacterial groups at the different levels of classification was observed on the corals. Corals do not appear, at present, to be stressed by climate induced changing environmental conditions in the upper Porcupine Bank Canyon. Overall, the corals in the Porcupine Bank Canyon are in a healthy state despite the detection of pathogenic bacterial groups. However, the current trend of climate change and subsequent deep-sea warming could shift the bacterial composition towards a more dominant pathogenic bacterial community, with serious implications for coral health and stability of this important ecosystem.

\section{Introduction}

Scleractinian corals are globally distributed and include cold-water and tropical corals ${ }^{1}$. Cold-water corals (CWCs) are greater in abundance in the northeast Atlantic ${ }^{2}$, including in submarine canyons, and provide several niches inhabited by diverse microbes such as archaea, bacteria as well as protists ${ }^{3}$. Microbes live in the mucus, the polyp tissues and on the coral skeleton as well as in the ambient environment of the corals ${ }^{4}$. Microbial diversity and its interaction with the host and the environment facilitates identification of important linkages existing between the microbial communities and macroecological change ${ }^{5,6,7}$. Climate change, sedimentation, nutrients, pollution, salinity and temperature ${ }^{8}$ disrupt the normal functioning of beneficial microbes ${ }^{9}$ by altering the microbial community during stressful conditions $10,11,12$. Changes in coral physiology affect the rate of mucus production and its biochemical composition ${ }^{13}, 5$, thereby favouring invading pathogens over resident microbes ${ }^{14}$. Also, while microbial assemblages support the growth and distribution of CWCs ${ }^{15}$, some are involved in biogeochemical processes, nutrients recycling and the breakdown of organic and waste products $16,17,18$.

The primary framework-forming coral in the Porcupine Bank Canyon (PBC) in the northeast Atlantic is the scleractinian coral Lophelia pertusa ${ }^{19}$. The distribution of L. pertusa (syn. Desmophllum pertusum ${ }^{20}$ ) colonies in the northeast Atlantic is influenced by microbes that live on them ${ }^{21}$ as research suggests that microbes living on Lophelia and other CWCs potentially bestow on them probiotic properties ${ }^{22,23}$. While 
there are differences in the coral-associated microbial communities of living, dead and fossilized Lophelia and the ambient environment $24,25,26,27$, no divergence has been observed between the different colour morphotypes of $L$. pertusa ${ }^{6}$. Also, species-specific distribution of cold-water coral-associated microbes has been reported ${ }^{6,18}$, whilst Lawler et al. ${ }^{17}$ has noted that microbial diversity is conserved across different species. Cold-water coral-associated microbial communities are involved in the formation of carbonate mounds ${ }^{28}$. According to Templer et al. ${ }^{28}$, these microbes bind mound sediment together through carbonate precipitation, which eventually help preserve the mound structure. Generally, research on the contributions of microbial communities on and/or within CWCs is limited. As a result, our understanding of the roles that microbes play in the ecology of CWCs are insufficient, making it imperative that we assess the essential roles that microbes play in the processes that drive changes in coral distributions in the deep-sea.

Different coral sampling strategies yield different results in microbial diversity ${ }^{29,} 30$. Microbial gene sequencing is relatively fast and efficient and can be used to screen microbes associated with corals. The 16S rRNA gene is the most widely used sequence for microbial community profiling, although the use of the internal transcribed spacer (ITS) region has also been reported ${ }^{31}$. The challenge with molecular techniques is that non-target genes can be amplified even when species-specific primers are used. Several culture-independent techniques have been used to characterise cold-water coral-associated microbial communities $21,28,6,14,17$. Culture-based methods have also been applied to evaluate coralassociated microbes ${ }^{32,33,34}$ although this approach of microbial community profiling is influenced by the type of medium used ${ }^{29}$. Also, marine microbes are generally difficult to grow on a medium. As such, a combination of both culture and culture-independent techniques has been advised as the use of only one of the methods in microbial studies can be limiting ${ }^{29}, 34$.

Next generation sequencing (NGS) is an advanced deep-sequencing technique and its application in coldwater (specifically in Lophelia pertusa and Madrepora oculata) coral-associated microbial community analysis is rather limited $22,35,16,36$. NGS is a high throughput technique which can sequence in parallel, millions of fragmented DNA from a single sample ${ }^{37}$. The NGS technique can detect microbes without prior knowledge of the target organism and discover novel organisms ${ }^{38}$, making its application suitable for environmental DNA samples ${ }^{39}$. Therefore, the present study aims to: 1 ) characterise the composition and diversity of microbial community in the PBC and, 2) determine the distribution of microbial communities in the corals, sediment and the ambient water in the PBC.

\section{Results}

In all, thirteen samples were successfully sequenced (seven coral and three each of water and sediment) (Tables 1 and Supplementary Table S1). A total of 2,586,928 raw sequences yielded 529,513 effective tags (across 13 samples) for sequence analysis after processing and quality filtering of raw reads (Table 1). A total of 4,494 sequence variants with mean length of 190 were observed. Also, the least ASVs was observed in HF5 (20,588 sequences) whilst the highest ASVs was observed in FF3 (75,473 sequences) 
after quality filtering with Dada2 (Table 1). A total of 522,608 ASVs were observed across the thirteen samples (Table 1). Among the three groups of samples, corals contained 272,411 ASVs, sediment 161,726 ASVs whereas water yielded 88,471 ASVs. Five ASVs were commonly observed across thirteen samples (Supplementary Table S2: Feature detail, frequency and number of samples observed in). One ASV occurred twice in eleven samples whilst 236 ASVs occurred twice in only one sample (Supplementary Table S2: Feature detail, frequency and number of samples observed in). Species distribution curves showed that all thirteen samples were sufficient to capture the different patterns of bacterial diversity (Supplementary Fig. S1).

Table 1

Groups of samples, site location, sample name, sample code, raw reads, input reads, Dada2 process and feature counts

\begin{tabular}{|c|c|c|c|c|c|c|c|}
\hline Group & $\begin{array}{l}\text { Sample } \\
\text { name }\end{array}$ & $\begin{array}{l}\text { Site } \\
\text { location }\end{array}$ & $\begin{array}{l}\text { Sample } \\
\text { code }\end{array}$ & $\begin{array}{l}\text { Raw } \\
\text { reads }\end{array}$ & $\begin{array}{l}\text { Input } \\
\text { reads }\end{array}$ & $\begin{array}{l}\text { Dada2 } \\
\text { process }\end{array}$ & $\begin{array}{l}\text { Feature } \\
\text { counts }\end{array}$ \\
\hline \multirow[t]{7}{*}{ G1 } & L. pertusa & Head & HF1 & 219,650 & 129,893 & 58,037 & 57,526 \\
\hline & L. pertusa & Head & HF5 & 268,660 & 140,849 & 20,588 & 18,151 \\
\hline & L. pertusa & South & SF3 & 219,146 & 126,146 & 63,808 & 63,500 \\
\hline & L. pertusa & South & SC1 & 212,669 & 119,902 & 56,263 & 56,056 \\
\hline & L. pertusa & South & SF4 & 140,528 & 80,414 & 40,060 & 39,311 \\
\hline & M. oculata & South & SF2 & 172,246 & 91,923 & 36,971 & 36,638 \\
\hline & M. oculata & Flank & FF3 & 216,965 & 130,280 & 75,473 & 73,600 \\
\hline \multirow[t]{3}{*}{ G2 } & Water & Head & W3 & 215,642 & 121,655 & 30,607 & 30,600 \\
\hline & Water & Flank & W6 & 122,749 & 67,180 & 20,995 & 20,991 \\
\hline & Water & South & W9 & 216,899 & 126,655 & 34,827 & 34,806 \\
\hline \multirow[t]{3}{*}{ G3 } & Sediment & Head & $\mathrm{CH} 1$ & 201,187 & 109,241 & 32,727 & 32,674 \\
\hline & Sediment & Flank & SS2 & 164,139 & 99,376 & 26,966 & 26,888 \\
\hline & Sediment & South & ss3 & 216,448 & 110,085 & 32,191 & 31,867 \\
\hline
\end{tabular}

Raw reads = original paired end reads after sequencing; Input reads = tags merged from trimmed raw reads before Dada2 processing; Dada2 process = output reads after Dada2 processing; Feature counts = amplicon sequence variants (ASVs) after filtering out unassigned. G1 = coral samples; G2 = water samples; G3 = sediment samples

\section{Alpha diversity indices}


Among groups of samples respectively, the observed Shannon's diversity $(H=3.56, P=0.17)$, Faith PD $\left(F \_P D=3.92, P=0.14\right)$ and Pielou's evenness $\left(J^{\prime}=3.10, P=0.21\right)$ were determined. Furthermore,

Shannon diversity $(H=4.38, P=0.11)$, Faith $P D\left(F \_P D=1.24, P=0.54\right)$ and Pielou's evenness $\left(J^{\prime}=2.53\right.$, $P=0.28)$ were estimated among the site locations, while Shannon's diversity $(H=3.43, P=0.06)$, Faith PD ( $\left.F \_P D=3.46, P=0.06\right)$ and Pielou's evenness $\left(J^{\prime}=3.43, P=0.06\right)$ were evaluated for the different coral species used in the present study. All pairwise comparisons were found not to be significant $(P>$ 0.05).

\section{Beta diversity indices}

Permutational multivariate analysis of variance (PERMANOVA, based on Bray-Curtis distance matrix) revealed that bacterial compositions among groups of samples were significant (Pseudo-F $=1.24, P=$ 0.04; all pairwise comparisons were not significant at $P>0.05$ ), while site locations (Pseudo- $F=0.95, P=$ 0.64; all pairwise comparisons were not significant at $P>0.05$ ) and the CWCs (Pseudo-F $=0.88, P=0.61$; all pairwise comparisons were not significant at $P>0.05$ ) showed no significant difference. Similarly, PERMANOVA based on unweighted UniFrac distance confirmed that there were significant differences $(P$ = 0.05; although pairwise comparisons were not significant) among the different groups of samples, but no divergence $(P>0.05)$ among site locations and the different coral species. A PCoA plot, that was made and visualised in Emperor, shows the relationship among microbial compositions on the different groups of samples from the PBC (Fig. 1).

\section{Taxonomic classification}

Proteobacteria dominated the bacterial communities across the thirteen different samples (coral, water and sediment) followed by Firmicutes (Fig. 2). Bacteroidetes (0.66 - 21.09\%) and Actinobacteria (0.25 $10.82 \%$ ) were also relatively abundant across all samples (Fig. 2). Chloroflexi was represented in high abundance (3.47\%) in sediment samples. Candidate phylum TM6 (name derived from Torf, Mittlere Schicht) was more abundant in sediment $(0.60-3.32 \%)$ than in corals $(<0.1 \%)$ and water $(<0.1 \%)$ samples while candidate phylum TM7 was more abundant in corals $(<0.1-1.59 \%)$ than water $(<0.1 \%)$ and sediment $(<0.1 \%$ ) samples (Fig. 2). Fusobacteria, Lentisphaerae, Elusimicrobia, Cladithrix, Fibrobacteres and Synergistetes were observed only in corals at $<0.1 \%$. Also, Chlorobi and Chlamydiae were present only in sediment at $<0.1 \%$ while SAR406 was observed only in water samples at $<0.01 \%$. Planctomycetes, Tenericutes were observed in corals and sediment samples at $<0.1 \%$ (Fig. 2). The highest abundance of Proteobacteria observed in Madrepora and Lophelia were $96.23 \%$ and $67.89 \%$ respectively. Fusobacteria $(>0.1 \%)$ and TM7 $(>1 \%)$ were observed in only Lophelia samples and at the canyon head (Fig. 2).

At the order-level of bacterial classification, Clostridiales (9.11 $\pm 2.94 \%)$, Bacteroidales $(4.51 \pm 1.93 \%)$, Flavobacteriales $(3.60 \pm 1.29 \%)$, Rhodobacterales (3.60 $\pm 1.29 \%)$, Rickettsiales $(3.43 \pm 2.93 \%)$, Xanthomonadales $(2.12 \pm 0.59 \%)$ and Acidomicrobiales $(2.00 \pm 0.78 \%)$ were consistently represented in 
high abundances in all corals (i.e., $100 \%$ coral sample coverage) (Fig. 3). They were also highly abundant in non-coral samples Conversely, Sphingobacterales (1.38 $\pm 0.46 \%)$, Oceanospirillales $(1.23 \pm 0.41 \%)$, Verrucomicrobiales (1.14 $\pm 0.50 \%)$, Myxococcales (1.01 $\pm 0.34 \%)$, Burkholderiales $(0.54 \pm 0.26 \%)$, NB1-j $(0.45 \pm 0.16 \%)$, Campylobacterales $(0.30 \pm 0.11 \%)$, and Coriobacterales $(0.15 \pm 0.07 \%)$, were represented in relatively low abundances in all corals and much lower in non-corals except Oceanospirillales (Fig. 3). The bacterial groups Rhizobiales, Rhodospiralles, Spirochaetales, Legionalles, Enterobacteriales, Actinomycetales occur in six of the seven coral samples albeit in low abundances and a couple of the non-coral samples (Fig. 3). Members belonging to the genera Pseudomonas $(0.24 \pm 0.08 \%$ ), Pseudoalteromonas $(0.59 \pm 0.14 \%)$ and Photobacterium $(0.53 \pm 0.13 \%)$ were relatively abundant among the corals and even more abundant in the non-coral samples.

Generally, archaea are only found in the total sample in low abundances $(<5 \%)$ with the phylum Thaumarchaeota (25.92 - 100\%) dominant among the archaea communities, although not observed in all samples. Parvarchaea was identified in three samples in relatively low abundance (Fig. 4).

Methanomicrobia (5.12\%) was found only in SS3 (sediment sample) while FF3 (Madrepora coral sample) contained only Thermoplasmata (100\%) (Fig. 4). Samples W3 and HF5 are not represented in Fig. 4 probably because no archaeal communities were identified.

\section{Discussion}

Seabed morphology is known to influence the dynamics of the physical and chemical properties (e.g. dissolved and particulate organic matter, oxygen saturation and current regimes) of the deep-sea 40 including the upper PBC ${ }^{41}$. These properties can potentially influence the composition of microbial communities on CWCs, sediment and the ambient water ${ }^{26,6}$. Coral microbiologists have recognised that there is divergence among microbial communities inhabiting corals, sediments and the ambient water ${ }^{24}$. In the present study, divergence in the microbial composition associated with the scleractinian corals, water and sediment samples were observed in the upper PBC (Fig. 1C). However, there was no divergence in the microbial communities in relation to site locations and coral species (Figs. 1A and B), even though geographical distribution can cause differences in host-bacterial composition ${ }^{36}$. In this context, observations in relation to CWCs in the present study should be interpreted with caution as only two samples of Madrepora oculata were used.

Shannon's diversity observed for CWCs in the present study seems to be higher than what has been reported in some microbial studies ${ }^{3,16}$ yet similar to other research ${ }^{17,36}$. Röthig et al. ${ }^{18}$ and Hansson et al. ${ }^{24}$ observed species-specific differences in coral-associated bacterial composition as well as divergence in bacterial composition across corals and water samples. Meistertzheim et al. ${ }^{16}$ reason that differences in the feeding strategies and thermal tolerance between the framework-forming corals $L$. pertusa and M. oculata are responsible for the structure observed in the host-bacterial community composition. In line with Neulinger et al. ${ }^{21}$, this study suggests that variations in water mass does not play a major role in structuring the bacterial communities across the different samples as these were 
collected between $600-800 \mathrm{~m}$, where the only prevailing water mass is the Eastern North Atlantic Water ${ }^{19}$. Nevertheless, inherent local physical conditions (e.g., salinity, pH, temperature and oxygen saturation 14,10 ) might have contributed to the observed divergence in microbial composition across the different samples in the present study.

In the present study, Alteromonadales were abundant in non-coral (water and sediment) samples while unclassified Gammaproteobacteria were abundant in corals. Also, between the two coral species, we observed that unclassified Gammaproteobacteria were more abundant in M. oculata than in L. pertusa. In general, we observed that CWCs showed high microbial diversity compared to the surrounding environments. Similarly, Schöttner et al. ${ }^{26}$ noticed that bacterial communities associated with coral habitats were significantly more biodiverse than those associated with non-coral habitats due to mucus release of corals which dissolves in the water and can fuel the growth of microbes. Scleractinian corals can produce and release dissolved and particulate organic matter in the form of mucus 42,43 , which microbes use as a source of carbon for growth ${ }^{44}$.

Coral associated microbial communities perform different functions that are important to the coral host and ensure the general health and existence of the corals ${ }^{45}$. The order-level bacterial communities including Clostridiales, Flavobacteriales, Rhodobacterales and Rickettsiales were consistently represented in relatively high abundance. However, Clostridiales, although detected in great quantity in this study, are generally highly abundant in diseased corals ${ }^{46}$. Bacteroidales are often associated with diseased corals 9,46 while some members are recognised for their antimicrobial protein production ${ }^{47}$. Some members of Flavobacteriales contain genes that can perform nitrogen cycling while others have been used for contaminant removal ${ }^{48,49}$. That said, pathogenic forms have also been identified ${ }^{50}$ as being overrepresented in stressed corals ${ }^{18}$. They have been observed in both azooxanthallate cold-water and zooxanthallate tropical corals ${ }^{51}$.

Neulinger et al. ${ }^{21}$, associated the distribution of Lophelia pertusa phenotypes in the northeastern Atlantic with the high Rhodobacterales abundance found on the species. According to Neulinger et al. ${ }^{21}$, the efficiency of the Rhodobacterales on white Lophelia allows it to adopt to areas of low organic materials in the deep-seas of the northeastern Atlantic and hence their dominance in this part of the ocean. Rhodobacterales are generally widespread in marine environments including on CWCs ${ }^{25}, 17$. They have been described as sulfur-and metal-reducing bacterial taxon, are involved in carbon cycling and can be applied as probiotics ${ }^{52}$. As this bacterial group occur in high abundance in the present study, it is likely they aid in growth and nutrition of the corals. Also, white Lophelia seems to be the dominant phenotype in the PBC, suggesting that Rhodobacterales may indeed be involved in Lophelia distribution in the northeast Atlantic

Members belonging to the order Rickettsiales have been described as opportunistic, facultative and pathogenic ${ }^{53,54}$, can be found in CWCs ${ }^{34}$ and have been associated with hydrocarbon contamination ${ }^{55}$. Rickettsiales have also been observed in tropical corals ${ }^{56}$ and found in high abundance in healthy corals 
57. It is interesting to note that even though the majority of bacterial groups that form the core microbiome in the present study have members which are pathogenic, only a few pathogenic members of Myxococcales have been characterised ${ }^{58}$. This bacterial order is ubiquitous and can tolerate extreme environments. They can prey on bacteria and so have been applied as antibiotic, cytotoxic and antiviral compounds ${ }^{59}$. Myxococcales are also involved in breakdown of organic carbon and nutrient cycling 60 and have been observed in coral species ${ }^{61}$. Many of the bacterial groups identified in this study including Burkholderiales, Rhizobiales, Sphingobacterales, Flavobacteriales and Oceanospirillales have been described to be associated with petroleum hydrocarbons ${ }^{55}$. However, there is no data from the upper PBC that suggest that petroleum exploration has been carried out in and around the canyon or that seabed pockmarks formed by hydrocarbon seepage are present. As such their presence may be related to a different function other than oil-degradation. Furthermore, the fact that many of these bacterial order occur in relatively low abundance seem not to be a petroleum degradation characteristic of corals from the upper PBC. It is probable that the dominant bacterial groups detected in the corals in this study are rather involved in the nutrition and growth of these species as suggested by other researchers $21,16,36$. This claim can be substantiated from the actively growing and well developed CWCs, especially $L$. pertusa as observed in the upper $\mathrm{PBC}{ }^{19,41}$.

Two commonly described bacterial genera Propionibacterium and Endozoicomonas in Lophelia from the Trondheimsfjord ${ }^{21}$, Rockall Bank ${ }^{35}$, Mediterranean ${ }^{16}$ and western Atlantic ${ }^{36}$ were not found in our samples. Also, Mycoplasma was reported to be part of L. pertusa microbiome 29, 25, 21 although not observed in this study nor in a study by Meistertzheim et al. ${ }^{16}$. Also, Novosphingobium which was characterised to be part of $L$. pertusa core microbiome ${ }^{36}$ was observed in only two sediment samples (SS2 and SS3) in this study while other studies on the same species failed to discover it, either on the coral or the surrounding environment ${ }^{21,35}$. Interestingly, we observed TM7, which was first recorded by Neulinger et al. ${ }^{21}$ in CWCs from the Trondheimsfjord and later by Van Bleijswijk et al. ${ }^{35}$ from the Rockall Bank. Neulinger et al. ${ }^{21}$ noted the possible similarities in cross-taxa bacterial composition, as TM7 had previously been observed in the sponge Chondrilla nucula ${ }^{62}$. Also, there seem to be a regional effect in the distribution of TM7 as it was observed in the northeastern Atlantic (this study; ${ }^{21,35}$ ), western Atlantic 25 but not the Mediterranean ${ }^{16}$. That said, it is difficult to draw regional trends and patterns from hostbacterial composition. Meistertzheim et al. ${ }^{16}$ and Kellogg et al. ${ }^{36}$ have highlighted methodological variations in bacterial community profiling as possible reason for the compositional differences. For example, host-bacterial compositional disparities can arise from unique regions of the 16S RNA gene ${ }^{63}$, microbial database used and/or number of sequences per sample ${ }^{36}$, sampling technique ${ }^{25}$ and sequencing platform and/or bioinformatic software ${ }^{64,65}$. We find that the cross-taxa phenomenon described by Neulinegr et al. ${ }^{21}$ to be most likely the case. The dominant microbial groups associated with the CWCs L. pertusa and M. oculata were Proteobacteria, Acidobacteria, Gemmatimonadetes, Actinobacteria, Thaumarchaea, which have also been found in sponges from reef environments in the deep-sea ${ }^{66,21,35,36}$. Recently, Rix et al. ${ }^{43}$ described how coral mucus nourishes different sponge species. 
The interaction between corals and sponges through mucus release demonstrates the importance of corals to the sponge-bacterial community and possibly other reef-associated organisms. For instance, the bacterium Tenacibaculum maritimum was represented in the corals in low abundance. This species can cause diseases in reef fishes ${ }^{67}$.

Generally in the corals, relatively high abundances of bacteria belonging to the genera Pseudomonas, Pseudoalteromonas and Photobacterium were observed. They form part of the core microbiome (100\% coral samples coverage). Species of Pseudoalteromonas are clinically relevant and perform probiotic functions ${ }^{68}$. P. porphyrae has the potential to increase the growth of some marine species in a stressful environment while $P$. luteoviolacea is shown to produce antibacterial compounds ${ }^{69,70}$. P. luteoviolacea was observed in the scleractinian corals Porites. lutea ${ }^{63}$, L. pertusa ${ }^{33}$ and in the present study. Also, Pseudomonas has been observed in CWCs ${ }^{3,16}$. It is ubiquitous, possesses probiotic properties and has been reported in soft corals ${ }^{71}$. Members of the genus Photobacterium are opportunistic with some holding probiotic properties ${ }^{72}$. Photobacterium in a symbiotic relationship with host organism can aid chitin digestion ${ }^{73}$. Röthig et al. ${ }^{18}$ identified $P$. angustum as part of the core microbiome $(100 \%$ coral samples coverage) whilst $P$. angustum and $P$. damselae were observed in a few samples in low abundances in the present study. $P$. angustum can suppress virulence genes ${ }^{74}$ while $P$. damselae is pathogenic ${ }^{75}$.

Also in this study, the genus Vibrio including $V$. shilonii $(0.22 \%)$ were observed in a couple of coral samples, which contradicts the findings of researchers who have described Vibrio usually as part of the core microbiome ${ }^{76}$. That said, both genera Vibrio and Photobacterium belong to the family Vibronaceae and have been characterised as opportunistic pathogens whose virulence is influenced by the environment ${ }^{77,21}$. For example $P$. damselae and $V$. shilonii can cause harm to their hosts in warm environments ${ }^{77}$, suggesting that their pathogenic activities to the CWCs are somewhat being suppressed by the cold temperatures of the deep. Several members of Vibrio also have probiotic properties, digestive enzymes (e.g. amylase, lipase, cellulase and chitinase) that aid in digestion, fix nitrogen in anoxic or limiting oxygen conditions ${ }^{73}$, and have been observed in healthy and/or diseased tropical corals ${ }^{33}$ as well as CWCs ${ }^{35,17}$. It is thus more likely that the bacterial species $P$. damselae, Tenacibaculum maritimum and $V$. shilonii observed in the present study (where only healthy corals were collected) are opportunistic pathogens that only contribute to the overall health of the corals. Other recognised important pathogenic species represented in a few samples in low abundance include Flexispiras rappini, Serratia mercens, Helicobacter cinaedi and Salmonella enterica, Cardiobacterium valvarum. Nevetheless, the relatively low abundant pathogenic bacterial species render them less important to the general health and functioning of the corals compared to the more abundant and dominant probiotic bacterial groups which play a major role in disease-prevention, nutition, and growth of the corals in the PBC.

Many archaeal taxa have been identified in CWCs (this study; ${ }^{35}$ ). Thaumarchaeota was represented in high abundance in all the coral samples except HF5 while Thermoplasmata was the only taxon present in sample FF3 (Madrepora sample). Both Thaumarchaeota and Thermoplasmata were identified in 
Lophelia samples from the Rockall Bank ${ }^{35}$. Members of this taxon can extract and metabolise amino acids from the water column as well as reduce sulfur ${ }^{78}$. Lophelia as an opportunistic feeder can take up dissolved amino acids from the water column and incorporate them into its cells ${ }^{79,80}$. Thus, the dominance of Thaumarchaeota on the coral samples could be a selective mechanism which parallels with the feeding strategy of Lophelia. Our work corroborates with Van Bleijswijk et al. ${ }^{35}$ who identified Thaumarchaeota as the single most important dominant archaeal taxa of CWCs (e.g. L. pertusa). Also, Parvarchaea has been described to be associated with petroleum hydrocarbon ${ }^{55}$. Interestingly, we note that all archaea in FF3 (Madrepora coral sample) from the flank are Thermoplasmata which is absent from SF2 (Madrepora coral sample), but highly abundant in only SS2 (sediment sample) which is also from the flank, suggesting that Thermoplasmata could be more associated with location in the canyon rather than the corals.

The current trends of deep-sea warming due to climate change and anthropogenic activities (e.g. deepsea mining and bottom-fishing ${ }^{81}$ ) put the corals in a vulnerable state, considering that most of the pathogenic microbes observed can cause disease in warmer and polluted environments. Although the coral microbiome suggests the coral are healthy with low abundances of pathogen, higher abundances of pathogens observed in the surrounding water and sediment suggest that this may change if corals become stressed. Appropriate measures ought to be implemented to reverse the current trends of climate change to protect the teeming corals of the deep or risk losing them, a situation that can arise from a shift from a generally benign and useful host-associated microbial community to pathogenic and disease-causing microbes as have been described for tropical corals elsewhere 9, 46 .

\section{Conclusions}

Our study is the first to describe the coral-associated microbiome from the Porcupine Bank Canyon. We characterised the pattern of distribution of microbial communities associated with coral and non-coral samples and their composition based on distances among samples in the upper PBC. We observed that the host-bacterial composition exhibited significant divergence among the different groups of samples, with coral samples showing high bacterial diversity. Comparing coral and non-coral assemblages, opportunistic pathogens are common in the water column and sediment. The dominance of pathogens in the water or sediment put the healthy corals at risk. Also, there was no structure in the bacterial composition associated with Lophelia pertusa and Madrepora oculata as well as in relation to site location in the canyon.

It is recognised that opportunistic pathogenic bacterial communities can pose a greater threat in warmer environments. Although it is difficult to predict the direction of the microbial composition inhabiting these corals in the short term, we believe that current trends of climate change and resulting deep-sea warming may shift the bacterial composition towards a more dominant virulent and pathogenic community. As such, it is important to protect the vulnerable coral fauna through policies that would reverse current trends in climate change to ensure the future safety of this fragile coral ecosystem. 


\section{Methodology}

\section{Study site, sample collection and storage}

Coral samples were collected within a $100 \mathrm{~m}$ periphery of three primary locations in the upper $\mathrm{PBC}$ in separate areas: canyon head $\left(52^{\circ} 13.6371,14^{\circ} 55.5389\right)$, canyon flank $\left(51^{\circ} 52.20624,15^{\circ} 02.0148\right)$ and south branch $\left(51^{\circ} 58.40933,15^{\circ} 02.4996\right)$ as defined by Appah et al. ${ }^{19}$ (Supplementary Table S1 and Supplementary Fig. S2). The PBC is tectonically controlled and terrestrially disconnected. The canyon head is sediment dominated and exhibits a gentle slope while the flank reveals a steep slope with exposed bedrock. The south branch is a smaller canyon system feeding into the main canyon and contains both live and dead coral communities ${ }^{82,19}$. Coral samples were collected between $607-721 \mathrm{~m}$ depth with an average salinity and temperature of 36.3 psu and $9.3^{\circ} \mathrm{C}$, respectively. Healthy looking $L$. pertusa and M. oculata samples were collected with an ROV-guided manipulator arm and stored in bioboxes. Coral samples collected for molecular work were stored in $100 \%$ ethanol at $-40^{\circ} \mathrm{C}$ for the duration of the cruise. Seawater samples (one at each site location) were collected with a 5 litre (I) ROV Niskin bottles (in the vicinity of the coral colonies) and stored in 1 litre sterile bottles while sediment samples (one at each site location) were collected with push cores and stored in 1 litre sterile zip-lock bags. Ambient seawater and sediment samples collected were stored at $-40^{\circ} \mathrm{C}$. All samples were collected between the 15-17/05/2019.

\section{DNA extraction of coral, sediment, and seawater samples}

All procedures were performed in a laminar flow hood which, along with the tools used, was decontaminated with a $10 \%$ bleach solution and DNA AWAY ${ }^{\circledR}$ before and between each sample preparation and each set of extractions. Coral samples were crushed to a fine powder using liquid nitrogen and aliquots of sediment were weighed to the required amount (200-250 mg) for DNA extraction. Extractions were performed using the DNeasy PowerSoil Pro kit (Qiagen) following manufacturer's protocol. DNA from seawater samples was extracted using DNeasy ${ }^{\circledR}$ Blood and Tissue kit (Qiagen) following the methodology outlined in Spens et al. ${ }^{83}$. Specifically, seawater samples were filtered over sterile $0.22 \mu \mathrm{m}$ Sterivex ${ }^{T M}$-GP filters (Merck Millipore, Germany) using $60 \mathrm{ml}$ syringes (SoftJect ${ }^{\circledR}, \mathrm{HSW}$, Tuttlingen, Germany). After filtering, one opening of the Sterivex ${ }^{T \mathrm{M}}-\mathrm{GP}$ filters was sealed with parafilm, $720 \mu$ of ATL-buffer and $80 \mu \mathrm{l}$ of proteinase $\mathrm{K}$ were added, the opening sealed, and the mixture was incubated at $56^{\circ} \mathrm{C}$ for $2 \mathrm{~h}$ with agitation. The buffer mix was transferred with a $3 \mathrm{ml} \mathrm{leuer-lock}{ }^{\mathrm{Tm}}$ syringe into a $2 \mathrm{ml}$ Eppendorf tube. DNA extraction was continued following the manufacturer's protocol, with buffer volumes adjusted for the amounts of lysate recovered from the sterivex filter column. All extractions were run alongside negative controls using $\mathrm{ddH}_{2} \mathrm{O}$ so that any laboratory contamination would be detected.

To test whether all the DNA yielded during the extraction process was entirely from the samples (and not from laboratory contamination), DNA extractions and negative controls were subjected to routine PCR of 
the 16s rRNA gene using the universal primers $8 \mathrm{~F}$ (5'-AGAGTTTGATCCTGGCTCAG-3') and $1492 \mathrm{R}\left(5^{\prime}\right.$ GGTTACCTTGTTACGACTT-3'). Negative controls did not yield any product indicating that sample DNA was suitable for further analysis. Genomic DNA samples were sent to Novogene, Cambridge, UK for microbial amplicon-based metagenomics sequencing $16 \mathrm{~S}$ (V3-V4). The purity and concentration of genomic DNA samples were assessed on a 1\% agarose gel and Qubit Fluorometer (Invitrogen, USA) respectively. The $341 \mathrm{~F}$ (5'-CCTAYGGGRBGCASCAG-3') and $806 \mathrm{R}$ (5'-GGACTACNNGGGTATCTAAT-3') primers with barcodes were used to amplify the V3-V4 region (466 bp) of the 16S rRNA gene and sequenced using the Illumina NovaSeq 6000 SP with paired ends ( $2 \times 250$ bp) strategy (Novogene, Cambridge, UK). PCR reactions were performed in a $20 \mu \mathrm{l}$ reaction volume using the Phusion ${ }^{\circledR}$ HighFidelity PCR Master Mix (New England Biolabs) with 1-2 ng template DNA. The final primer concentration was adjusted to $0.5 \mu \mathrm{M}$. Amplicons were run on a $2 \%$ agarose gel for detection, desired bands were excised and purified using Qiagen Gel Extraction Kit (Qiagen, Germany).

\section{Bioinformatic analysis and statistics}

Raw reads were quality controlled with FastQC 0.11 .9 , trimmed (to remove reads shorter than $200 \mathrm{bp}$, mean quality score of 30 in a sliding window of $10 \mathrm{bp}$ and a maximum of two primer mismatch) with Trimmomatic 0.39 and merged into contigs using FLASH 1.2.11. Quality filtering of the sequence data to remove chimeras was performed using Dada 2 as implemented in qualitative insights into microbial ecology (QIIME 2) v2020.8 ${ }^{84}$. Sequencing data were rarefied to a sample depth of 20,000 corresponding to the least number of sequences available for all thirteen samples. Each Dada 2 amplicon sequence variants (ASVs) were utilized for taxonomic classification via the QIIME 2 feature-classifier with the sklearn technique. Taxonomic assignment was made from the Greengenes 13_8 database (DeSantis et

al. ${ }^{85}$; based on $99 \%$ similarity of sequence data to the Greengenes database). All unassigned, mitochondrial and chloroplast ASVs were filtered out. Also, archaeal ASVs were filtered out and analysed separately for taxonomic classification.

Diversity indices of the samples were assessed using the QIIME 2 pipeline (https://docs.qiime2.org). The sequences were aligned using Mafft and FastTree to construct a phylogenetic tree. Alpha diversity indices (Shannon, Pielou's evenness and Faith phylogenetic index) were assessed to determine the microbial diversity within each sample. Beta diversity based on Bray-Curtis distance and unit fraction analyses were performed. Principal coordinates analysis (PCoA) plots were made in QIIME 2 and using the Emperor tool, the differences in microbial composition among groups of samples, the different species and site locations were visualised. Significant differences among groups of samples, types of species and site locations were evaluated using PERMANOVA. Also, Kruskal-Wallis test was used to compare alpha diversity indices among groups of samples, the different species and site locations.

\section{Declarations}

\section{Acknowledgements}


The authors thank the crew and officers of RV Celtic Explorer and ROV Holland 1 for their support and advice during data acquisition in the Porcupine Bank Canyon. Ship time on the RV Celtic Explorer was funded by the Marine Institute under the 2017 and 2018 Ship Time Programme of the National Development. The authors thank the funders of MMMonKey_Pro project (grant number: 16/IA/4528) Science Foundation Ireland (SFI), Geological Survey Ireland and the Marine Institute. This project also contributed to the EU iAtlantic project (grant agreement: 818123).

\section{Author Contributions}

JA: design, write up, data analysis, and data collection. ED: technical advice and draft editing. AL: data collection and processing. RO'R: technical advice and draft editing. LO'R: data collection. LM: data collection. AW: technical advice and draft editing. All authors contributed to the success of the manuscript.

\section{Additional Information}

Raw sequence data determined in this study are yet to be deposited in a recognised database

\section{Supplementary information}

Supplementary Table 2 will be presented as a separate excel file.

\section{Competing Interests:}

The authors declare no competing financial interests.

\section{References}

1. Roberts, J.M., Wheeler, A.J. \& Freiwald, A. Reefs of the deep: the biology and geology of cold-water coral ecosystems. Science, 312, 543-547 (2006).

2. Roberts, J.M., Wheeler, A., Freiwald, A. \& Cairns, S. Cold-water corals: the biology and geology of deep-sea coral habitats (Cambridge University Press, Cambridge, 2009).

3. Kellogg, C.A., Ross, S.W. \& Brooke, S.D Bacterial community diversity of the deep-sea octocoral Paramuricea placomus. PeerJ, 4, e2529 (2016).

4. Ainsworth, T.D., et al. The coral core microbiome identifies rare bacterial taxa as ubiquitous endosymbionts. The ISME journal, 9(10), 2261-2274 (2015).

5. Ainsworth, T.D., Thurber, R.V. and Gates, R.D. The future of coral reefs: a microbial perspective. Trends in Ecology \& Evolution, 25(4), 233-240 (2010). 
6. Schöttner, S., Wild, C., Hoffmann, F., Boetius, A. \& Ramette, A. Spatial scales of bacterial diversity in cold-water coral reef ecosystems. PloS one, 7(3), e32093 (2012).

7. Jensen, S., Lynch, M.D., Ray, J.L., Neufeld, J.D. \& Hovland, M. Norwegian deep-water coral reefs: cultivation and molecular analysis of planktonic microbial communities. Environmental microbiology, 17(10), 3597-3609 (2015).

8. Zaneveld, J.R., et al. Overfishing and nutrient pollution interact with temperature to disrupt coral reefs down to microbial scales. Nature communications, 7(1), 1-12 (2016).

9. Thurber, R.V., et al. Metagenomic analysis of stressed coral holobionts. Environmental Microbiology, 11(8), 2148-2163 (2009).

10. Röthig, T., Ochsenkühn, M.A., Roik, A., Van Der Merwe, R. \& Voolstra, C.R., Long-term salinity tolerance is accompanied by major restructuring of the coral bacterial microbiome. Molecular Ecology, 25(6), 1308-1323 (2016).

11. McDevitt-Irwin, J.M., Baum, J.K., Garren, M. \& Vega Thurber, R.L., Responses of coral-associated bacterial communities to local and global stressors. Frontiers in Marine Science, 4, p.262 (2017).

12. Zaneveld, J.R., McMinds, R. \& Thurber, R.V., Stress and stability: applying the Anna Karenina principle to animal microbiomes. Nature microbiology, 2(9), 1-8 (2017).

13. Fitt, W.K., et al. Response of two species of Indo-Pacific corals, Porites cylindrica and Stylophora pistillata, to short-term thermal stress: The host does matter in determining the tolerance of corals to bleaching. Journal of experimental marine biology and ecology, 373(2), 102-110 (2009).

14. Vezzulli, L., Pezzati, E., Huete-Stauffer, C., Pruzzo, C. \& Cerrano, C. 16SrDNA pyrosequencing of the Mediterranean gorgonian Paramuricea clavata reveals a link among alterations in bacterial holobiont members, anthropogenic influence and disease outbreaks. PloS one, 8(6), p.e67745 (2013).

15. Weinbauer, M.G., Ogier, J. and Maier, C. Microbial abundance in the coelenteron and mucus of the cold-water coral Lophelia pertusa and in bottom water of the reef environment. Aquatic Biology, 16(3), 209-216 (2012).

16. Meistertzheim, A.L., et al. Patterns of bacteria-host associations suggest different ecological strategies between two reef building cold-water coral species. Deep Sea Research Part I: Oceanographic Research Papers, 114, 12-22 (2016).

17. Lawler, S.N., et al. Coral-associated bacterial diversity is conserved across two deep-sea AnthothelaFrontiers in microbiology, 7, p.458 (2016).

18. Röthig, T., Yum, L.K., Kremb, S.G., Roik, A. \& Voolstra, C.R. Microbial community composition of coldwater corals from the Red Sea provides insight into functional adaption to a unique environment. Scientific Reports, 7(1), 1-9 (2017).

19. Appah, J.K.M., et al. Are non-reef habitats as important to benthic diversity and composition as coral reef and rubble habitats in submarine canyons? Analysis of controls on benthic megafauna distribution in the Porcupine Bank Canyon, NE Atlantic. Front. Mar. Sci. 7, doi: 10.3389/fmars.2020.571820 (2020). 
20. Addamo, A. M., et al Merging scleractinian genera: the overwhelming genetic similarity between solitary Desmophyllum and colonial Lophelia. BMC Evol. Biol. 16:108 (2016).

21. Neulinger, S.C., Järnegren, J., Ludvigsen, M., Lochte, K. \& Dullo, W.C. Phenotype-specific bacterial communities in the cold-water coral Lophelia pertusa (Scleractinia) and their implications for the coral's nutrition, health, and distribution. Applied and Environmental Microbiology, 74(23), 7272-7285 (2008).

22. Emblem, Å., et al. Mitogenome polymorphism in a single branch sample revealed by SOLiD deep sequencing of the Lophelia pertusa coral genome. Gene, 506(2), 344-349 (2012).

23. Sarmiento-Vizcaíno, A., et al. Pharmacological potential of phylogenetically diverse Actinobacteria isolated from deep-sea coral ecosystems of the submarine Avilés Canyon in the Cantabrian Sea. Microbial ecology, 73(2), 338-352 (2017).

24. Hansson, L., Agis, M., Maier, C. \& Weinbauer, M.G. Community composition of bacteria associated with cold-water coral Madrepora oculata: within and between colony variability. Marine Ecology Progress Series, 397, 89-102 (2009).

25. Kellogg, C.A., Lisle, J.T. \& Galkiewicz, J.P. Culture-independent characterization of bacterial communities associated with the cold-water coral Lophelia pertusa in the Northeastern Gulf of Mexico. Environ. Microbiol., 75(8), 2294-2303 (2009).

26. Schöttner, S., et al. Inter-and intra-habitat bacterial diversity associated with cold-water corals. The ISME journal, 3(6), 756-759 (2009).

27. Hoshino, T., et al. Comparative study of subseafloor microbial community structures in deeply buried coral fossils and sediment matrices from the challenger mound in the porcupine seabight. Frontiers in microbiology, 2, p.231 (2011).

28. Templer, S.P., Wehrmann, L.M., Zhang, Y., Vasconcelos, C. \& McKenzie, J.A., 2011. Microbial community composition and biogeochemical processes in cold-water coral carbonate mounds in the Gulf of Cadiz, on the Moroccan margin. Marine Geology, 282, 138-148 (2011).

29. Kellogg, C.A. Microbial ecology of Lophelia pertusa in the Northern Gulf of Mexico. Characterization of Northern Gulf of Mexico Deepwater Hard Bottom Communities with Emphasis on Lophelia CoralLophelia Reef Megafaunal Community Structure, Biotopes, Genetics, Microbial Ecology, and Geology (2004-2006): USGS Open-File Report, 1148, 2008-2015 (2008).

30. Sweet, M.J., Croquer, A. \& Bythell, J.C. Bacterial assemblages differ between compartments within the coral holobiont. Coral Reefs, 30(1), 39-52 (2011).

31. Brown, M.V. and Fuhrman, J.A. Marine bacterial microdiversity as revealed by internal transcribed spacer analysis. Aquatic Microbial Ecology, 41(1), 15-23 (2005).

32. Brück, T.B., Brück, W.M., Santiago-Vázquez, L.Z., McCarthy, P.J. \& Kerr, R.G. Diversity of the bacterial communities associated with the azooxanthellate deep water octocorals Leptogorgia minimata, Iciligorgia schrammi, and Swiftia exertia. Marine Biotechnology, 9(5), 561-576 (2007).

33. Galkiewicz, J.P., Pratte, Z.A., Gray, M.A. \& Kellogg, C.A. Characterization of culturable bacteria isolated from the cold-water coral Lophelia pertusa. FEMS microbiology ecology, 77(2), 333-346 (2011). 
34. Gray, M.A., Stone, R.P., McLaughlin, M.R. \& Kellogg, C.A. Microbial consortia of gorgonian corals from the Aleutian Islands. FEMS Microbiology Ecology, 76(1), 109-120 (2011).

35. Van Bleijswijk, J.D.L., et al. Microbial assemblages on a cold-water coral mound at the SE Rockall Bank (NE Atlantic): interactions with hydrography and topography. Biogeosciences Discussions, 12(2) (2015).

36. Kellogg, C.A., Goldsmith, D.B. \& Gray, M.A. Biogeographic comparison of Lophelia-associated bacterial communities in the western Atlantic reveals conserved core microbiome. Frontiers in Microbiology, 8, p.796 (2017).

37. Bertelli, C. and Greub, G. Rapid bacterial genome sequencing: methods and applications in clinical microbiology. Clinical Microbiology and Infection, 19(9), 803-813 (2013).

38. Motro, Y. and Moran-Gilad, J. Next-generation sequencing applications in clinical bacteriology. Biomolecular detection and quantification, 14, 1-6 (2017).

39. Cui, Q., Fang, T., Huang, Y., Dong, P. \& Wang, H. Evaluation of bacterial pathogen diversity, abundance and health risks in urban recreational water by amplicon next-generation sequencing and quantitative PCR. Journal of Environmental Sciences, 57, 137-149 (2017).

40. Levin, L.A., Sibuet, M., Gooday, A.J., Smith, C.R. \& Vanreusel, A. The roles of habitat heterogeneity in generating and maintaining biodiversity on continental margins: an introduction. Marine Ecology, 31(1), 1-5 (2010).

41. Lim, A., et al. Influence of benthic currents on cold-water coral habitats: a combined benthic monitoring and 3D photogrammetric investigation. Scientific Reports, 10(1), 1-15 (2020).

42. Tremblay, P., Grover, R., Maguer, J.F., Legendre, L. \& Ferrier-Pagès, C Autotrophic carbon budget in coral tissue: a new 13C-based model of photosynthate translocation. Journal of Experimental Biology, 215(8), 1384-1393 (2012).

43. Rix, L., et al. Coral mucus fuels the sponge loop in warm-and cold-water coral reef ecosystems. Scientific reports, 6(1), 1-11 (2016).

44. Taniguchi, A., Yoshida, T., Hibino, K. \& Eguchi, M. Community structures of actively growing bacteria stimulated by coral mucus. Journal of Experimental Marine Biology and Ecology, 469, 105-112 (2015).

45. Reshef, L., Koren, O., Loya, Y., Zilber-Rosenberg, I. and Rosenberg, E. The coral probiotic hypothesis. Environmental microbiology, 8(12), 2068-2073 (2006).

46. Meyer, J.L., et al. Microbial community shifts associated with the ongoing stony coral tissue loss disease outbreak on the Florida Reef Tract. Frontiers in Microbiology, 10, p.2244 (2019).

47. Roelofs, K.G., Coyne, M.J., Gentyala, R.R., Chatzidaki-Livanis, M. \& Comstock, L.E. Bacteroidales secreted antimicrobial proteins target surface molecules necessary for gut colonization and mediate competition in vivo. MBio, 74) (2016).

48. Sang, M.K. and Kim, K.D. The volatile-producing Flavobacterium johnsoniae strain GSE09 shows biocontrol activity against Phytophthora capsici in pepper. Journal of applied microbiology, 113(2), 383-398 (2012). 
49. Yang, J.A., Yang, S.H., Kim, J., Kwon, K.K. \& Oh, H.M. Comparative genome analysis of the Flavobacteriales bacterium strain UJ101, isolated from the gut of Atergatis reticulatus. Journal of Microbiology, 55(7), 583-591 (2017).

50. Declercq, A.M., Haesebrouck, F., Van den Broeck, W., Bossier, P. \& Decostere, A. Columnaris disease in fish: a review with emphasis on bacterium-host interactions. Veterinary research, 44(1), 1-17 (2013).

51. Penn, K., Wu, D., Eisen, J.A. \& Ward, N. Characterization of bacterial communities associated with deep-sea corals on Gulf of Alaska seamounts. Applied and Environmental Microbiology, 72(2), 16801683 (2006).

52. Brinkhoff, T., et al. Antibiotic production by a Roseobacter clade-affiliated species from the German Wadden Sea and its antagonistic effects on indigenous isolates. Applied and environmental microbiology, 70(4), 2560-2565 (2004).

53. Miller, M.W., Lohr, K.E., Cameron, C.M., Williams, D.E. \& Peters, E.C. Disease dynamics and potential mitigation among restored and wild staghorn coral, AcroporaPeerJ, 2, p.e541 (2014).

54. Peters, E. A Rickettsiales-like (?) bacterium is responsible for the tissue loss diseases of Caribbean acroporid corals. In Proceedings of the Ocean Science Meeting(pp. 23-28) (2014).

55. Simister, R.L., Antzis, E.W. \& White, H.K. Examining the diversity of microbes in a deep-sea coral community impacted by the Deepwater Horizon oil spill. Deep Sea Research Part II: Topical Studies in Oceanography, 129, 157-166 (2016).

56. Klinges, J.G., et al. Phylogenetic, genomic, and biogeographic characterization of a novel and ubiquitous marine invertebrate associated Rickettsiales parasite, Candidatus Aquarickettsia rohweri, gen. nov., sp. nov. The ISME journal, 13(12), 2938-2953 (2019).

57. Godoy-Vitorino, F., Ruiz-Diaz, C.P., Rivera-Seda, A., Ramírez-Lugo, J.S. \& Toledo-Hernández, C. The microbial biosphere of the coral Acropora cervicornis in Northeastern Puerto Rico. PeerJ, 5, p.e3717 (2017).

58. Parkinson, T. J. Specific Infectious Diseases Causing Infertility and Subfertility in Cattle. Veterinary Reproduction and Obstetrics, 434-466.doi:10.1016/b978-0-7020-7233-8.00024 (2019).

59. Garcia, R. and Müller, R. The family myxococcaceae. The Prokaryotes, 10, 191-212 (2014).

60. Baker, B.J., Lazar, C.S., Teske, A.P. \& Dick, G.J. Genomic resolution of linkages in carbon, nitrogen, and sulfur cycling among widespread estuary sediment bacteria. Microbiome, 3(1), p.14 (2015).

61. Bayer, T., et al. Bacteria of the genus Endozoicomonas dominate the microbiome of the Mediterranean gorgonian coral Eunicella cavolini. Marine Ecology Progress Series, 479, 75-84.77 (2013).

62. Thiel, V., Leininger, S., Schmaljohann, R., Brümmer, F. \& Imhoff, J.F. Sponge-specific bacterial associations of the Mediterranean sponge Chondrilla nucula (Demospongiae, Tetractinomorpha). Microbial Ecology, 54(1), 101-111 (2007).

63. Pootakham, W., et al. High resolution profiling of coral-associated bacterial communities using fulllength 16S rRNA sequence data from PacBio SMRT sequencing system. Scientific Reports, 7(1), 1-14 (2017). 
64. Bailén, M., Bressa, C., Larrosa, M. \& González-Soltero, R. Bioinformatic strategies to address limitations of 16rRNA short-read amplicons from different sequencing platforms. Journal of Microbiological Methods, 169, p.105811 (2020).

65. Kaszubinski, S.F., et al. Evaluating Bioinformatic Pipeline Performance for Forensic Microbiome Analysis. Journal of Forensic Sciences, 65(2), 513-525 (2020).

66. Yakimov, M.M., et al. Phylogenetic survey of metabolically active microbial communities associated with the deep-sea coral Lophelia pertusa from the Apulian plateau, Central Mediterranean Sea. Deep Sea Research Part l: Oceanographic Research Papers, 53(1), 62-75 (2006).

67. International Council for the Exploration of the Sea. Tenacibaculum maritimum, causal agent of tenacibaculosis in marine fish. Original by Santos Y., F. Pazos and J. L. Barja (No. 55), Revised by Simon R. M. Jones and Lone Madsen. ICES Identification Leaflets for Diseases and Parasites of Fish and Shellfish. No. 70. 5 pp http://doi.org/10.17895/ices.pub.4681 (2019).

68. Holmström, C. and Kjelleberg, S. Marine Pseudoalteromonas species are associated with higher organisms and produce biologically active extracellular agents. FEMS microbiology ecology, 30(4), 285-293 (1999).

69. Dimitrieva, G.Y., Crawford, R.L. \& Yüksel, G.Ü. The nature of plant growth-promoting effects of a pseudoalteromonad associated with the marine algae Laminaria japonica and linked to catalase excretion. Journal of Applied Microbiology, 100(5), 1159-1169 (2006).

70. Vynne, N.G., Månsson, M., Nielsen, K.F. \& Gram, L. Bioactivity, chemical profiling, and 16S rRNA-based phylogeny of Pseudoalteromonas strains collected on a global research cruise. Marine Biotechnology, 13(6), 1062-1073 (2011).

71. Salasia, S.I.O. Antibacterial property of marine bacterium Pseudomonas sp. associated with a soft coral against pathogenic Streptococcus equi zooepidemicus. Journal of Coastal Development, 11(3), 113-120 (2008).

72. Austin, B., Stuckey, L.F., Robertson, P.A.W., Effendi, I. \& Griffith, D.R.W. A probiotic strain of Vibrio alginolyticus effective in reducing diseases caused by Aeromonas salmonicida, Vibrio anguillarum and Vibrio ordalii. Journal of Fish Diseases, 18(1), 93-96 (1995).

73. Itoi, S., Okamura, T., Koyama, Y. \& Sugita, H. Chitinolytic bacteria in the intestinal tract of Japanese coastal fishes. Canadian journal of microbiology, 52(12), 1158-1163 (2006).

74. Mansson, M., et al. Inhibition of virulence gene expression in Staphylococcus aureus by novel depsipeptides from a marine photobacterium. Marine drugs, 9(12), 2537-2552 (2011).

75. Rivas, A.J., Lemos, M.L. \& Osorio, C.R. Photobacterium damselae subsp. damselae, a bacterium pathogenic for marine animals and humans. Frontiers in microbiology, 4, p.283 (2013).

76. Daniels, C.A., et al. Spatial heterogeneity of bacterial communities in the mucus of Montastraea annularis. Marine Ecology Progress Series, 426, 29-40 (2011).

77. Rosenberg, E. and Falkovitz, L. The Vibrio shiloil Oculina patagonica model system of coral bleaching. Rev. Microbiol., 58, 143-159 (2004). 
78. Beam, J.P., Jay, Z.J., Kozubal, M.A. \& Inskeep, W.P. Niche specialization of novel Thaumarchaeota to oxic and hypoxic acidic geothermal springs of Yellowstone National Park. The ISME journal, 8(4), 938-951 (2014).

79. Gori, A., Grover, R., Orejas, C., Sikorski, S. \& Ferrier-Pagès, C. Uptake of dissolved free amino acids by four cold-water coral species from the Mediterranean Sea. Deep Sea Research Part Il: Topical Studies in Oceanography, 99, 42-50 (2014).

80. Mueller, C.E., Larsson, A.I., Veuger, B., Middelburg, J.J. \& Van Oevelen, D. Opportunistic feeding on various organic food sources by the cold-water coral Lophelia pertusa. Biogeosciences, 11(1), p.123 (2014).

81. Wagner, D., et al. Coral reefs of the high seas: hidden biodiversity hotspots in need of protection. Frontiers in Marine Science, 7, p.776 (2020).

82. Mazzini, A., Akhmetzhanov, A., Monteys, X. \& Ivanov, M. The Porcupine Bank Canyon coral mounds: oceanographic and topographic steering of deep-water carbonate mound development and associated phosphatic deposition. Geo-Marine Letters, 32(3), 205-225 (2012).

83. Spens, J., et al. Comparison of capture and storage methods for aqueous macrobial eDNA using an optimized extraction protocol: Advantage of enclosed filter. Methods in Ecology and Evolution, 8(5), 635-645 (2017).

84. Bolyen, E., et al. Reproducible, interactive, scalable and extensible microbiome data science using QIIME 2. Nature biotechnology, 37(8), 852-857 (2019).

85. DeSantis, T.Z., et al. Greengenes, a chimera-checked 16S rRNA gene database and workbench compatible with ARB. Applied and environmental microbiology, 72(7), 5069-5072 (2006).

\section{Figures}



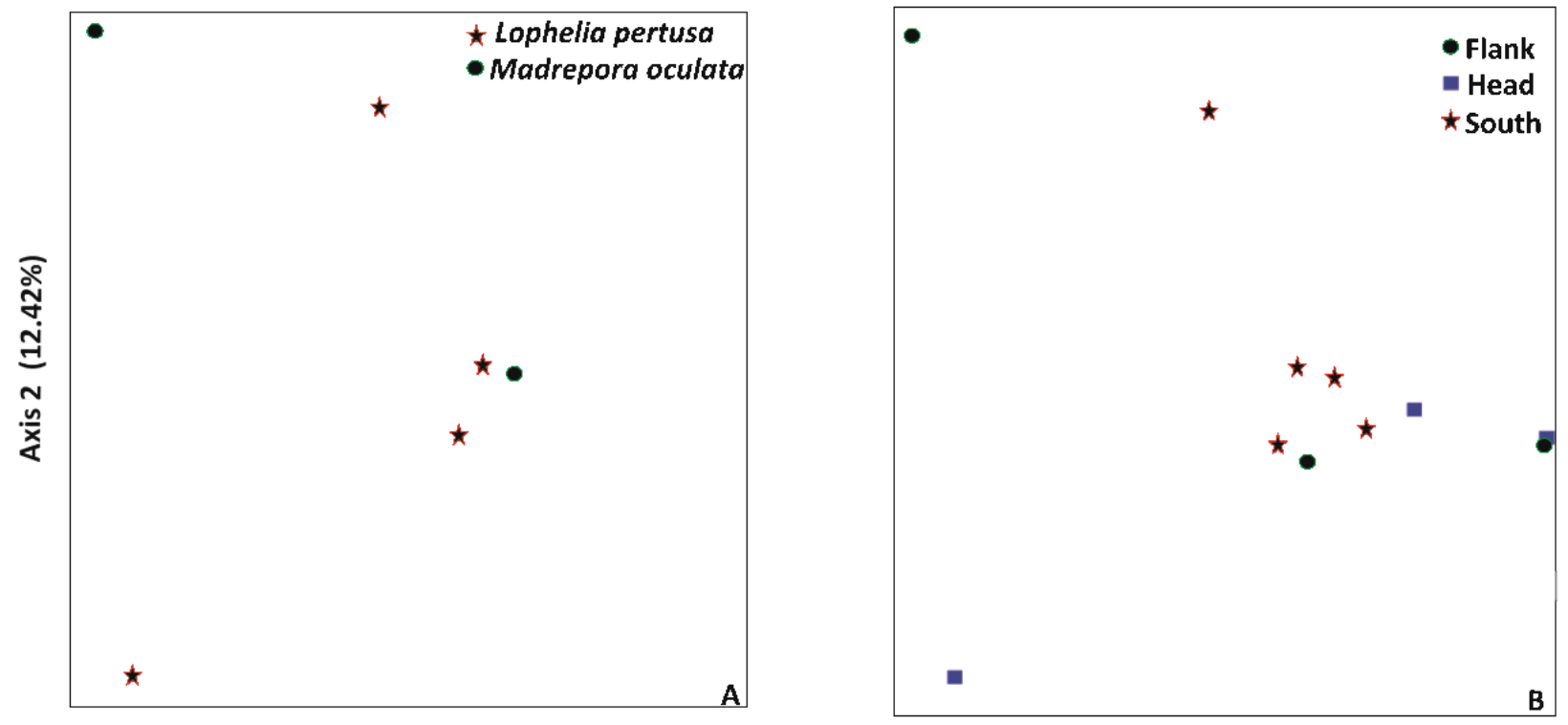

Axis 1 (16.11\%)

Axis 1 (16.11\%)

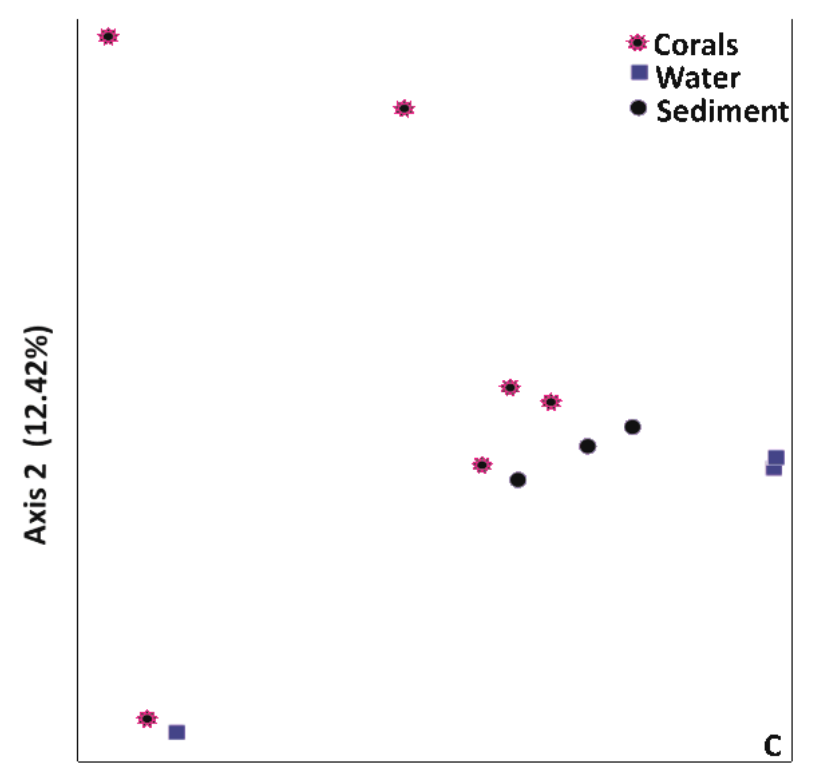

Axis 1 (16.11\%)

\section{Figure 1}

Principal coordinates analysis (PCoA, based on Bray-Curtis distance) plot of microbial composition among A) cold-water corals, B) site locations and, C) groups of samples. 


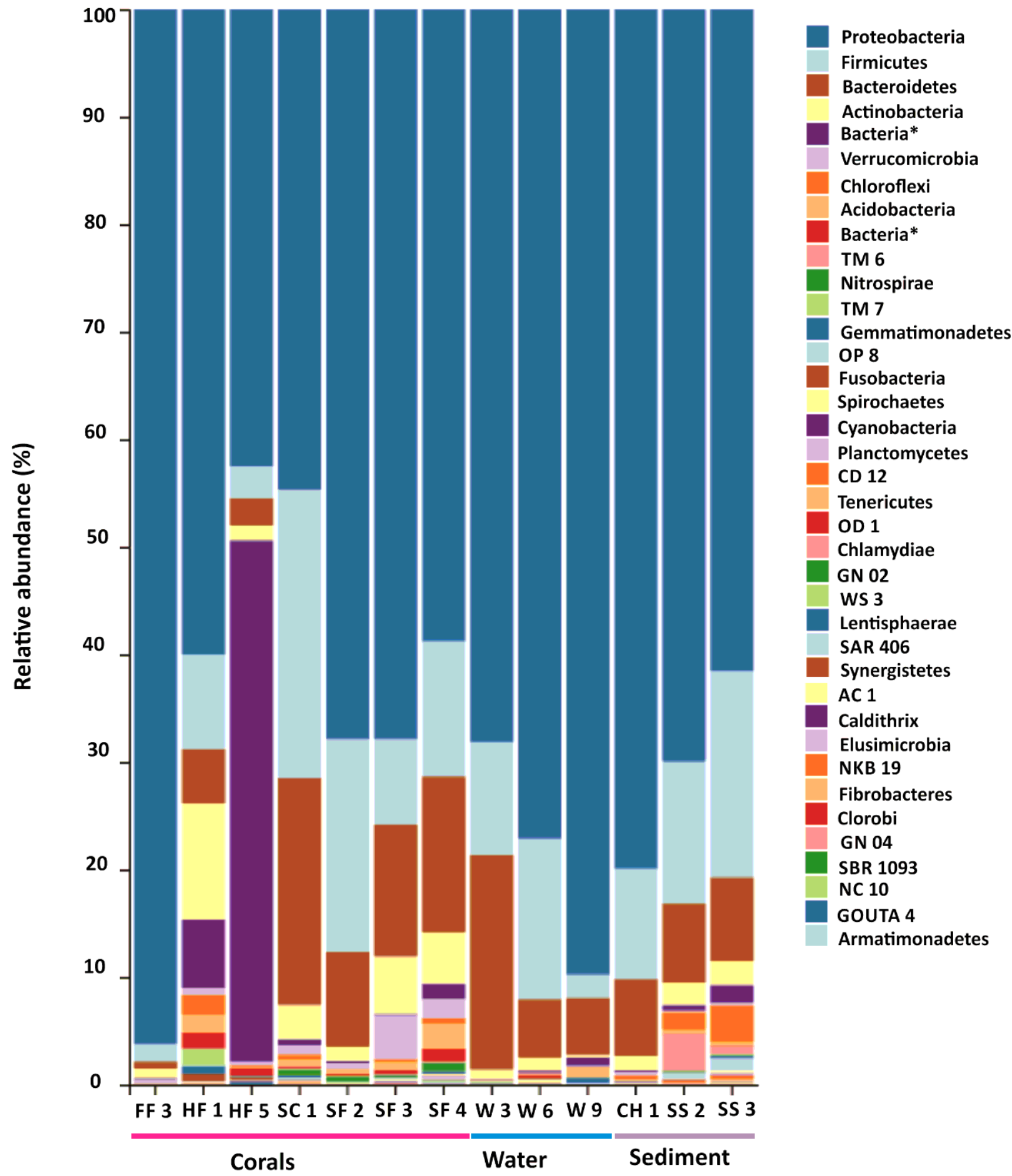

Figure 2

Relative abundances of bacterial taxa at phylum-level composition in cold-water corals, water, and sediment samples in the upper PBC. * represents unclassified taxa. 


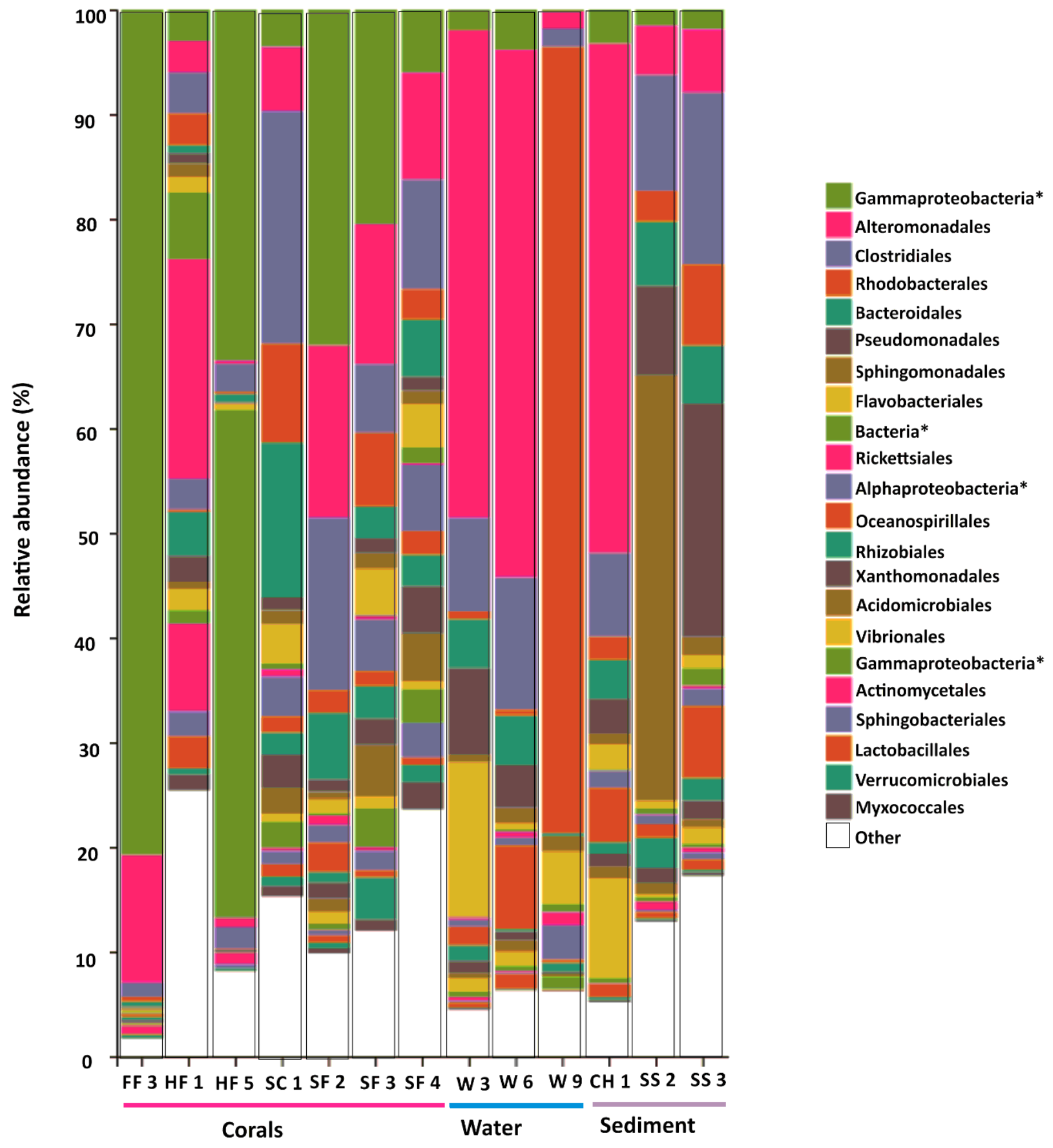

Figure 3

Relative abundances of bacterial taxa at order-level of bacterial community composition in cold-water corals, water, and sediment samples in the upper PBC. * represents unclassified taxa. 


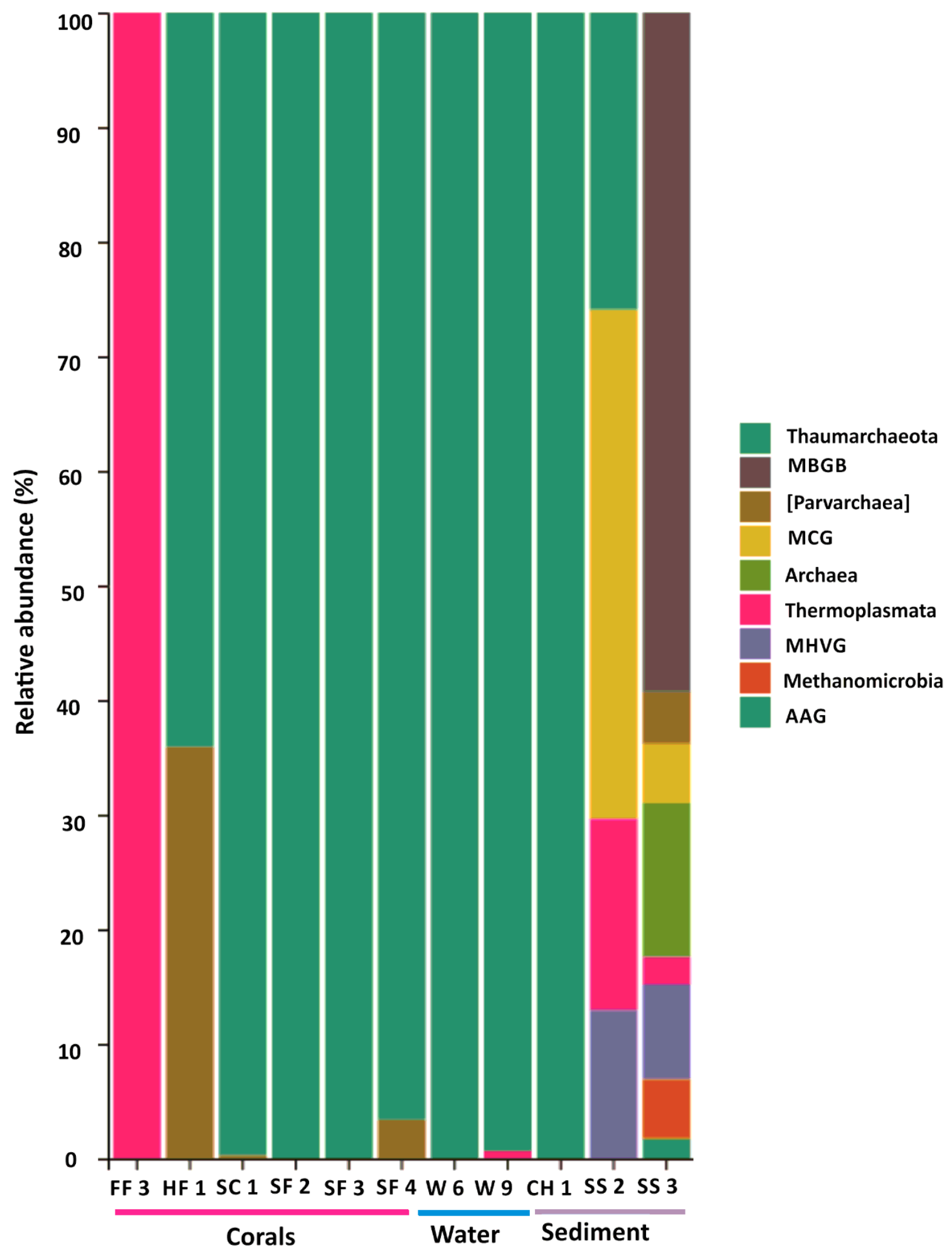

Figure 4

Relative abundances of archaeal taxa at phylum-level composition in cold-water corals, water, and sediment samples in the PBC.

Supplementary Files 
This is a list of supplementary files associated with this preprint. Click to download.

- featuredetailfrequencynumberofsamplesobservedin.xlsx

- supplementaryinformation.docx 